\title{
Pretreatment serum lactate level as a prognostic biomarker in patients undergoing supratentorial primary brain tumor resection
}

\author{
Chung-Chih Shih ${ }^{1}$, Tzong-Shiun Lee ${ }^{1}$, Fon-Yih Tsuang ${ }^{2}$, Pei-Lin Lin ${ }^{1}$, Ya-Jung \\ Cheng ${ }^{1}$, Hsiao-Liang Cheng ${ }^{1, *}$ and Chun-Yu Wu ${ }^{1, *}$ \\ ${ }^{1}$ Department of Anesthesiology, National Taiwan University Hospital, Taipei, Taiwan \\ ${ }^{2}$ Division of Neurosurgery, Department of Surgery, National Taiwan University Hospital, Taipei, Taiwan \\ *These authors have contributed equally to this work \\ Correspondence to: Chun-YuWu, email: longersolo@gmail.com \\ Hsiao-Liang Cheng, email: B87401032@ntu.edu.tw \\ Keywords: lactate, brain tumor, tumor marker, prognostic factor, glioma \\ Received: March 09, $2017 \quad$ Accepted: June 05, $2017 \quad$ Published: June 29, 2017 \\ Copyright: Shih et al. This is an open-access article distributed under the terms of the Creative Commons Attribution License 3.0 \\ (CC BY 3.0), which permits unrestricted use, distribution, and reproduction in any medium, provided the original author and source \\ are credited.
}

\section{ABSTRACT}

Introduction: Malignant primary brain tumors are one of the most aggressive cancers. Pretreatment serum nonneuronal biomarkers closely associated with postoperative outcomes are of high clinical relevance. The present study aimed to identify potential pretreatment serum biomarkers that may influence oncological outcomes in patients with primary brain tumors.

Methods: A total of $\mathbf{7 4}$ patients undergoing supratentorial primary brain tumor resection were enrolled. Before tumor resection, serum neuronal biomarkers, namely neuron-specific enolase (NSE), S100 $\beta$, and glial fibrillary acidic protein (GFAP), and serum nonneuronal biomarkers, namely neutrophil gelatinase-associated lipocalin (NGAL), lactate dehydrogenase (LDH), and lactate, were measured and associated postoperative oncological outcomes, including brain tumor grading, progression-free survival (PFS), and overall survival (OS), were compared.

Results: Patients with high-grade brain tumors had significantly higher pretreatment serum lactate levels $(p=0.011)$. By contrast, other biomarkers were comparable between patients with high-grade and low-grade brain tumors. Receiver operating characteristic curve analysis of serum lactate levels yielded an area under the curve of 0.71 for differentiating between high-grade and low-grade brain tumors. Kaplan-Meier survival analysis revealed patients with high serum lactate levels $(\geqq 2.0$ $\mathrm{mmol} / \mathrm{L})$ had shorter PFS and OS ( $p=0.021$ and $p=0.093$, respectively). In a multiple regression model, only elevated serum lactate levels were associated with poor PFS and OS ( $p=0.021$ and $p=0.048$, respectively).

Conclusions: An elevated pretreatment serum lactate level is a prognostic biomarker of high-grade primary brain tumors and is significantly associated with poor PFS in patients with supratentorial brain tumors undergoing tumor resection. By contrast, other serum biomarkers are not significantly associated with oncological outcomes.

\section{INTRODUCTION}

The oncological outcomes for brain tumors remain poor even after a successful tumor resection. Serum biomarkers, which represent brain tumor severity and are associated with therapy, may not only improve differential diagnosis but also facilitate clinical management of patients with brain tumors. Elevated levels of several 
serum biomarkers, including neuronal and nonneuronal biomarkers, have been reported in patients with brain tumors. Serum neuronal biomarkers, such as neuronspecific enolase (NSE) [1], S100 $\beta$ [2], and glial fibrillary acidic protein (GFAP) [3, 4], have been reported to be upregulated in patients with brain tumors caused by brain injuries. However, the association between serum neuronal biomarkers and oncological outcomes after tumor resection has yet to be sufficiently investigated in patients with brain tumors.

Elevated levels of nonneuronal biomarkers, including tissue and urinary neutrophil gelatinaseassociated lipocalin (NGAL) and tissue lactate, have been reported in patients with brain tumors. NGAL is a member of the lipocalin protein family, and plays multifaceted roles in both physiological and pathological processes, such as inflammatory responses and cell proliferation. Higher tissue and urinary NGAL levels have been reported in patients with brain tumors $[5,6]$. However, as a bridge between tissue and urinary biomarkers, serum NGAL levels have been investigated insufficiently in patients with brain tumors.

In a tumor microenvironment, lactate is produced by tumor cells and immune cells through anaerobic glycolysis [7] catalyzed by lactate dehydrogenase (LDH). Accordingly, higher serum lactate levels were reported in patients before brain tumor resection [8], and higher serum LDH was related to oncological outcomes in patients with solid tumors [9]. However, the prognostic value of pretreatment serum lactate levels has yet to be compared with that of other serum biomarkers, particularly neuronal biomarkers. Therefore, this study investigated the potential pretreatment prognostic value of serum neuronal and nonneuronal biomarkers, namely NSE, S100 $\beta$, GFAP, NGAL, LDH, and lactate, in patients undergoing supratentorial primary brain tumor resection.

\section{RESULTS}

A total of 74 patients ( 23 men and 51 women) with solitary supratentorial gliomas were enrolled. Fifty-four patients had low-grade tumors, and 20 patients had highgrade tumors. Table 1 presents the patients' demographic data. No patients had sepsis or abnormal liver function before surgery. Serum lactate levels were significantly higher in the patients with high-grade brain tumors than in the patients with low-grade brain tumors $(1.91 \pm 1.06$ vs. $1.19 \pm 0.78 \mathrm{mmol} / \mathrm{L} ; p=0.011$; Table 1$)$. In addition, the patients with high-grade brain tumors tended to have lower serum GFAP than those with low-grade tumors $(0.145 \pm 0.354$ vs. $0.281 \pm 0.522 \mathrm{ng} / \mathrm{mL} ; p=0.097$; Table 1). Logistic regression analysis revealed that elevated serum lactate levels are an independent predictor of highgrade brain tumors (odds ratio, 2.89; 95\% confidence interval [CI], 1.485-2.62; $p=0.0018$; Table 2 ]. Receiver operating characteristic (ROC) curve analysis of serum lactate levels was performed to differentiate between highgrade and low-grade brain tumors (Figure 1). The area under the curve (AUC) was 0.705 (95\% CI, 0.586-0.804; $p=0.0055$ ). Pretreatment serum lactate levels (cutoff value, $2.0 \mathrm{mmol} / \mathrm{L}$ ) were determined to predict high-grade brain tumors (sensitivity, 45\%; specificity, 90.7\%).

Kaplan-Meier survival analysis revealed a significant relationship between pretreatment serum lactate levels ( $\geqq 2.0 \mathrm{mmol} / \mathrm{L}$ ) and oncological outcomes during a follow-up period of $248.5 \pm 118.9$ days (Figure 2). Patients with higher serum lactate levels had a tendency of shorter overall survival (OS), however, this did not reach statistical significance (Figure 2A; $p=0.093$ ). In addition, patients with higher serum lactate was associated with shorter progression-free survival (PFS) than those with lower serum lactate levels (Figure 2B; $p=0.021$ ).

Univariate analysis indicated that the male sex and higher serum lactate and NGAL levels are poor prognostic factors (Table 3). However, only the serum lactate level was an independent factor associated with poor OS (HR, $2.049 ; 95 \%$ CI, $1.006-4.174 ; p=0.048)$ in a multivariate Cox proportional hazards regression model. High serum lactate levels and the male sex were independently associated with poor PFS (HR, 1.658; 95\% CI, 1.0782.548; $p=0.021$ and HR, 2.951; 95\% CI, 1.161-7.496; $p$ $=0.023$, respectively).

\section{DISCUSSION}

The major finding of this study is that the pretreatment serum lactate level is a more valuable prognostic biomarker than other biomarkers, including neuronal (NSE, S100 $\beta$, and GFAP) and nonneuronal (NGAL and LDH) biomarkers, in patients with supratentorial primary brain tumors undergoing tumor resection.

The higher pretreatment serum lactate levels in patients with brain tumors may be produced by the metabolic processes of cancer cells and injured normal brain tissues. Cancer cells exhibit a high rate of aerobic glycolysis (Warburg effect), producing lactate that participates in tumor progression [10]. Lactate is not only a nutrient for tumor cells but also a signaling agent that promotes angiogenesis and an immunosuppressive metabolite [11, 12]. Therefore, lactate may be a key regulator of the glycolytic phenotype, which provides nutrients for tumor growth and metastasis. Consequently, massive lactate accumulation is a unique phenotype of cancer [13]. Furthermore, higher lactate levels and poorer patient outcomes have been significantly correlated [14]. For instance, an association between higher lactate levels in tumor tissues and shorter PFS has been widely reported in patients with gliomas [15-17], head and neck cancers [18, 19], and cervical cancer [20]. The present study revealed that the pretreatment serum lactate level is an independent predictor of poor outcomes in patients 
Table 1: Patient characteristics

\begin{tabular}{|c|c|c|c|}
\hline \multirow{2}{*}{ Characteristic } & High grade & Low grade & \multirow{2}{*}{$P$ Value } \\
\hline & $(\mathrm{N}=\mathbf{2 0})$ & $(\mathrm{N}=54)$ & \\
\hline Age (years) & $54.2 \pm 12.5$ & $57.4 \pm 10.9$ & 0.293 \\
\hline Male no. $(\%)$ & $8(40.0)$ & $15(27.8)$ & 0.398 \\
\hline Body weight (kg) & $58.9 \pm 8.7$ & $60.9 \pm 9.9$ & 0.455 \\
\hline \multicolumn{4}{|l|}{ Comorbidities, No. (\%) } \\
\hline Cardiovascular disease & $2(10.0)$ & $4(7.4)$ & 0.659 \\
\hline Hypertension & $5(75.0)$ & $9(16.7)$ & 0.308 \\
\hline Diabetes & $3(15)$ & $4(7.4)$ & 0.379 \\
\hline Other cancer & $1(5.0)$ & $4(7.4)$ & 0.589 \\
\hline Tumor size $(\mathrm{cm})$ & $4.50 \pm 1.78$ & $4.31 \pm 1.73$ & 0.450 \\
\hline \multicolumn{4}{|l|}{ WHO grade } \\
\hline $\mathrm{I} / \mathrm{II}$ & & $38 / 13$ & \\
\hline III/IV & $4 / 16$ & & \\
\hline \multicolumn{4}{|l|}{ Serum biomarkers } \\
\hline Lactate $(\mathrm{mmol} / \mathrm{L})$ & $1.91 \pm 1.06$ & $1.19 \pm 0.78$ & $0.011 *$ \\
\hline $\mathrm{LDH}(\mathrm{mU} / \mathrm{mL})$ & $39.62 \pm 31.28$ & $37.70 \pm 38.81$ & 0.401 \\
\hline NGAL $(\mathrm{mcg} / \mathrm{mL})$ & $0.544 \pm 0.536$ & $0.465 \pm 0.554$ & 0.516 \\
\hline GFAP (ng/L) & $0.145 \pm 0.354$ & $0.281 \pm 0.522$ & 0.097 \\
\hline $\mathrm{NSE}(\mathrm{mcg} / \mathrm{mL})$ & $10.77 \pm 14.68$ & $16.86 \pm 63.63$ & 0.339 \\
\hline $\mathrm{S} 100 \beta(\mathrm{pg} / \mathrm{mL})$ & $93.61 \pm 131.76$ & $84.59 \pm 129.06$ & 0.353 \\
\hline
\end{tabular}

WHO, World Health Organization; LDH, lactate dehydrogenase; NGAL, neutrophil gelatinase-associated lipocalin; GFAP, glial fibrillary acidic protein; NSE, neuron-specific enolase.

Continuous variables are expressed as the mean \pm standard deviation, whereas categorical variables are expressed as the number and percentage.

$* p<0.05$.

undergoing brain tumor resection. Because serum lactate levels have a positive linear correlation with tissue lactate levels [21], higher serum lactate levels are possibly representative of higher tissue lactate accumulation.

In addition to indicating the metabolism pathways of cancer cells, elevated baseline serum lactate levels in patients with brain tumors may represent the tumor burden on normal brain tissues. Serum lactate produced by tumor cells is associated with increased LDH levels. A recent meta-analysis showed that higher pretreatment serum LDH levels are associated with poorer oncological outcomes in patients with solid tumors [9]. Although pathologically high pretreatment LDH levels were observed in our study patients, pretreatment LDH levels were not associated with postoperative oncological outcomes, indicating that the association between pretreatment serum lactate levels and oncological outcomes may not be entirely related to tumor metabolism. Moreover, serum lactate accumulates under activated or pathological conditions in the brain, and can be rapidly released into the blood [22]. Therefore, part of the elevated serum lactate level may reflect the tumor burden on normal brain tissues.

Lactate accumulation is commonly elevated in high-grade brain tumors [23]. Our results regarding the association between serum lactate levels and brain tumor grading are consistent with a study by Ramamani et al., with comparable sensitivity (59.3\%) and specificity (95.7\%) for predicting high-grade brain tumors [8]. Compared with the aforementioned study, the present study not only evaluated more biomarkers but also enrolled more patients (50 vs. 74), and the cutoff value of serum lactate levels was calculated using a more robust statistical approach involving ROC curve analysis and multiple logistic regression. Although our results indicated that pretreatment serum lactate has high specificity in predicting tumor grade, it may be insufficiently sensitive. This may be because serum lactate could be elevated in patients with large, low-grade brain tumors, which have 
Table 2: Logistic regression analysis of the factors associated with high-grade

\begin{tabular}{|c|c|c|c|c|}
\hline \multirow{2}{*}{ Variable } & \multicolumn{2}{|c|}{ Univariate } & \multicolumn{2}{|c|}{ Multivariate } \\
\hline & Odds ratio (CI) & $P$ & Odds ratio (CI) & $P$ \\
\hline Age (years) & $0.976(0.933-1.021)$ & 0.291 & - & \\
\hline Sex (male:female) & $1.733(0.592-5.077)$ & 0.316 & - & \\
\hline Body weight (kg) & $0.979(0.926-1.034)$ & 0.438 & - & \\
\hline \multicolumn{5}{|l|}{ Comorbidities } \\
\hline $\begin{array}{l}\text { Cardiovascular } \\
\text { disease }\end{array}$ & $1.389(0.234-8.240)$ & 0.718 & - & \\
\hline Hypertension & $1.667(0.483-5.751)$ & 0.419 & - & \\
\hline Diabetes & $2.206(0.448-10.87)$ & 0.331 & - & \\
\hline Other cancer & $0.658(0.069-6.267)$ & 0.716 & - & \\
\hline Tumor size $(\mathrm{cm})$ & $1.065(0.793-1.431)$ & 0.675 & - & \\
\hline \multicolumn{5}{|l|}{ Serum biomarkers } \\
\hline Lactate $(\mathrm{mmol} / \mathrm{L})$ & $2.374(1.275-4.421)$ & $0.006 *$ & $2.890(1.485-2.621)$ & $0.002 *$ \\
\hline $\mathrm{LDH}(\mathrm{mU} / \mathrm{mL})$ & $1.001(0.988-1.015)$ & 0.841 & - & \\
\hline NGAL (ng/mL) & $1.297(0.519-3.242)$ & 0.578 & - & \\
\hline GFAP (mg/L) & $0.447(0.095-2.103)$ & 0.308 & $0.245(0.050-1.191)$ & 0.083 \\
\hline NSE (ng/mL) & $0.997(0.984-1.011)$ & 0.686 & - & \\
\hline $\mathrm{S} 100 \beta(\mathrm{pg} / \mathrm{mL})$ & $1.001(0.997-1.004)$ & 0.789 & - & \\
\hline
\end{tabular}

Abbreviations: HR, hazard ratio; CI, confidence interval; LDH, lactate dehydrogenase; NGAL, neutrophil gelatinaseassociated lipocalin; GFAP, glial fibrillary acidic protein; NSE, neuron-specific enolase.

$* p<0.05$.

a large tumor burden. The brain tumor grade is most sensitively diagnosed through imaging studies, such as magnetic resonance imaging. Because serum lactate is a convenient biomarker, combining the serum lactate level with imaging tools may assist physicians in clinical management or risk stratification before brain tumor resection.

Our result indicated that male sex may present as a risk factor of worse PFS and a tendency of worse overall survival which is consistent with one study revealing a worse survival after tumor resection surgery in male pediatric brain tumor patients [24]. This may be because the effects of sex are strong in particular subtypes of high-grade glioma. The mesenchymal, proneural, and neural subtypes of glioblastoma multiforme (GBM) exhibit a substantial difference in incidence between male and female patients (2:1) [25]. By contrast, the classical subtype occurs equally in males and females. These differences in cell type may be the reason behind the differences in oncological outcome between male and female patients.

The association between NGAL and solid tumors has received attention in recent years [6]. For instance, urinary NGAL was reported to be associated with brain tumors and decrease with treatment, and can be tracked from brain tumors to urine [5]. Accordingly, we observed that pretreatment serum NGAL levels were markedly elevated in patients with brain tumors. However, pretreatment serum NGAL levels were not associated with oncological outcomes, possibly because NGAL not only participates in tumor development but also exerts anticancer effects $[6,26]$. Therefore, the pretreatment serum NGAL level may not be a prognostic biomarker in patients with brain tumors.

In the present study, we observed that certain pretreatment serum neuronal biomarkers, namely NSE, S100 $\beta$, and GFAP, were not associated with postoperative oncological outcomes. Serum NSE has been widely reported as a tumor marker in diagnosis of brain metastases of small cell lung cancer [27] but not in primary brain tumors, it is possibly because changes in serum NSE levels are sensitive to damages in normal brain tissues caused by tumor compression. Serum S100 $\beta$ has been proposed as an early predictor of brain metastasis [28] and a prognostic factor for brain metastatic melanoma [29]. However, it was not a prognostic biomarker of primary brain tumors, potentially because $\mathrm{S} 100 \beta$ is less specific to neurons and is distributed in several cell tissues 


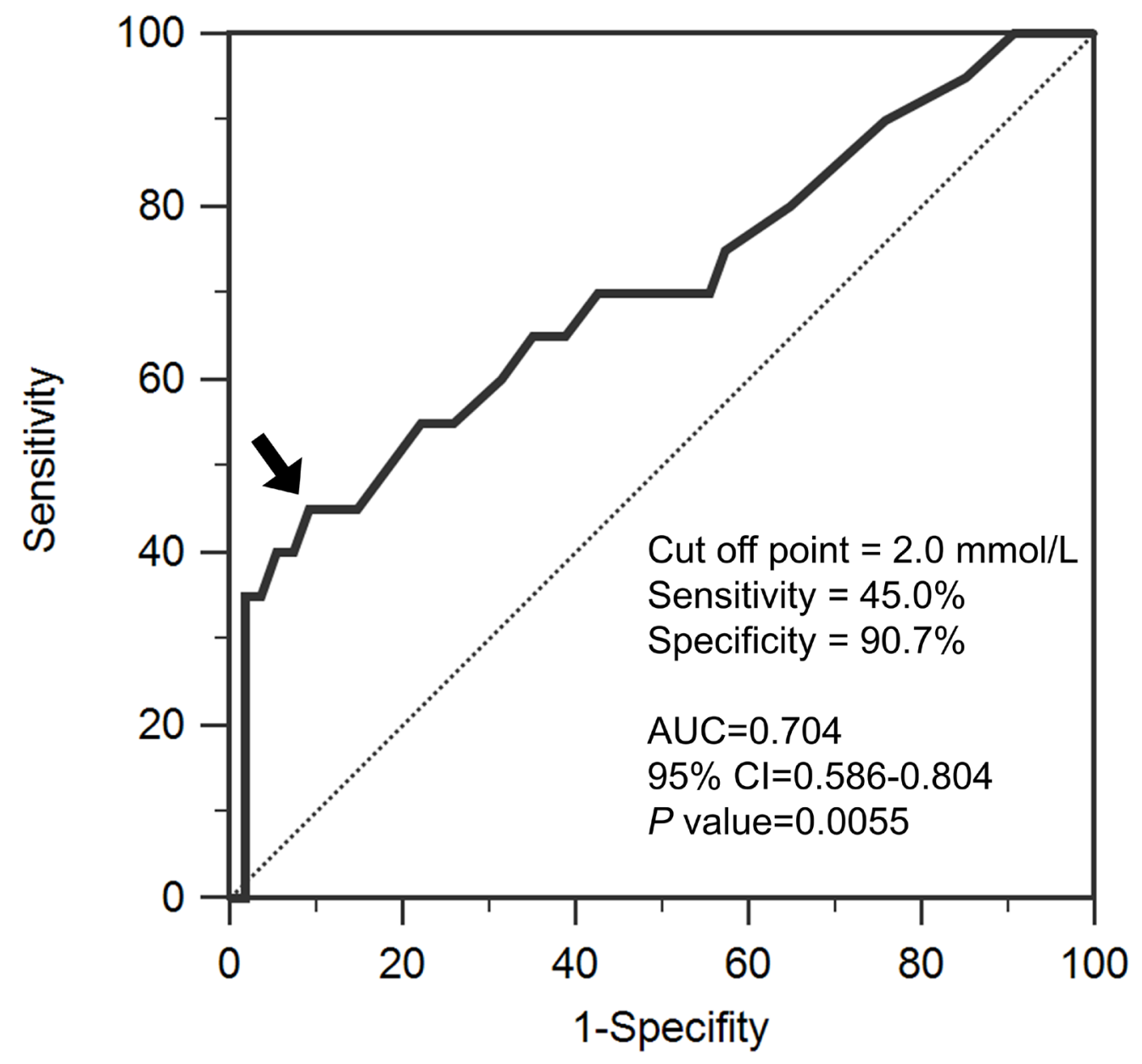

Figure 1: Receiver operating characteristic analysis of serum lactate levels for differentiating between high-grade and low-grade brain tumors. The area under the curve (AUC) is 0.705 ( $95 \%$ confidence interval [CI], 0.586-0.804). The arrow indicates the optimal cutoff value for lactate $(2.0 \mathrm{mmol} / \mathrm{L})$. The dotted line is the no-discrimination curve.
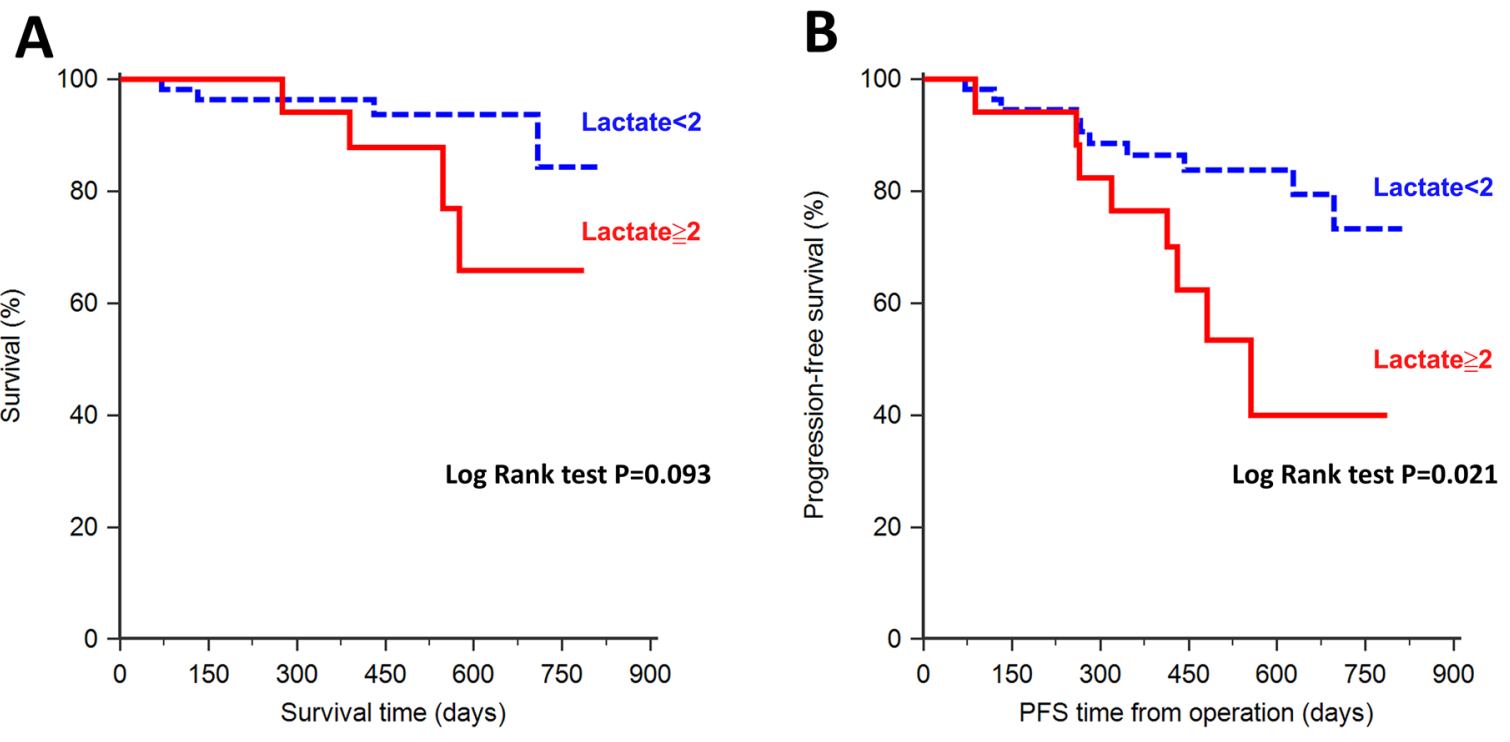

Figure 2: Kaplan-Meier analysis of serum lactate levels and patient survival. (A) Overall survival (OS) did not differ significantly between patients with high serum lactate levels $(\geqq 2.0 \mathrm{mmol} / \mathrm{L})$ and those with low serum lactate levels $(p=0.093)$. (B) Progression-free survival (PFS) differed significantly between patients with high serum lactate levels and those with low lactate levels $(p=$ 0.021). Patients with high serum lactate levels were associated with poor PFS after tumor resection. 
Table 3: Univariate and multivariate Cox regression analyses of overall survival and progression-free survival in patients with supratentorial primary brain tumors

\begin{tabular}{|c|c|c|c|c|c|c|}
\hline \multirow{3}{*}{ Factor } & \multicolumn{6}{|c|}{ Progression-free survival } \\
\hline & \multicolumn{3}{|c|}{ Univariate analysis } & \multicolumn{3}{|c|}{ Multivariate analysis } \\
\hline & HR & $95 \%$ CI & $P$ & HR & $95 \%$ CI & $P$ \\
\hline Age (years) & 1.029 & $0.985-1.076$ & 0.195 & - & - & - \\
\hline Sex (male: female) & 3.019 & $1.192-7.645$ & $0.020 *$ & 2.951 & $1.161-7.496$ & $0.023 *$ \\
\hline Body weight (kg) & 1.011 & $0.965-1.059$ & 0.647 & - & - & - \\
\hline Tumor size (cm) & 1.123 & $0.868-1.453$ & 0.378 & - & - & - \\
\hline \multicolumn{7}{|l|}{ Serum biomarkers } \\
\hline Lactate $(\mathrm{mmol} / \mathrm{L})$ & 1.619 & $1.079-2.428$ & $0.020 *$ & 1.658 & $1.078-2.548$ & $0.021 *$ \\
\hline LDH (mU/mL) & 1.009 & $0.999-1.019$ & 0.067 & - & - & - \\
\hline NGAL (ng/mL) & 2.062 & $0.993-4.279$ & 0.052 & - & - & - \\
\hline GFAP (mg/L) & 1.260 & $0.460-3.447$ & 0.653 & - & - & - \\
\hline NSE (ng/mL) & 0.998 & $0.989-1.008$ & 0.740 & - & - & - \\
\hline \multirow[t]{2}{*}{$\mathrm{S} 100 \beta(\mathrm{pg} / \mathrm{mL})$} & 1.001 & 0.997-1.004 & 0.733 & - & - & - \\
\hline & \multicolumn{6}{|c|}{ Overall survival } \\
\hline \multirow[t]{2}{*}{ Factor } & \multicolumn{3}{|c|}{ Univariate analysis } & \multicolumn{3}{|c|}{ Multivariate analysis } \\
\hline & HR & $95 \% \mathrm{CI}$ & $P$ & HR & $95 \%$ CI & $P$ \\
\hline Age (years) & 1.041 & $0.973-1.114$ & 0.247 & - & - & - \\
\hline Sex (male: female) & 4.349 & $1.037-18.247$ & $0.045^{*}$ & 3.785 & $0.903-15.859$ & 0.069 \\
\hline Body weight (kg) & 0.994 & $0.925-1.070$ & 0.881 & - & - & - \\
\hline Tumor size (cm) & 1.214 & $0.835-1.763$ & 0.310 & - & - & - \\
\hline \multicolumn{7}{|l|}{ Serum biomarkers } \\
\hline Lactate (mmol/L) & 2.046 & $1.078-3.886$ & $0.029 *$ & 2.049 & $1.006-4.175$ & $0.048 *$ \\
\hline $\mathrm{LDH}(\mathrm{mU} / \mathrm{mL})$ & 1.013 & $0.998-1.028$ & 0.084 & - & - & - \\
\hline NGAL (ng/mL) & 2.987 & $1.067-8.363$ & $0.037^{*}$ & - & - & - \\
\hline GFAP (mg/L) & 0.983 & $0.169-5.704$ & 0.985 & - & - & - \\
\hline NSE (ng/mL) & 0.936 & $0.867-1.069$ & 0.478 & - & - & - \\
\hline $\mathrm{S} 100 \beta(\mathrm{pg} / \mathrm{mL})$ & 0.997 & $0.987-1.006$ & 0.490 & - & - & - \\
\hline
\end{tabular}

Abbreviations: HR, hazard ratio; CI, confidence interval; LDH, lactate dehydrogenase; NGAL, neutrophil gelatinaseassociated lipocalin; GFAP, glial fibrillary acidic protein; NSE, neuron-specific enolase.

$* p<0.05$.

[30]. Several studies have suggested that the serum GFAP level is a potential prognostic factor in patients with primary brain tumors. For instance, GFAP was associated with tumor volume and histopathological tumor characteristics in GBM [4], whereas brain metastases did not increase blood GFAP levels [31]. Pretreatment serum GFAP levels were not significantly associated with postoperative oncological outcomes, possibly because the number of cells expressing GFAP is inversely proportional to the extent of anaplasia, and loss of GFAP expression is frequently observed in high-grade gliomas [32]. Despite GFAP lacking clinical prognostic value, our data are consistent with the aforementioned findings that patients with high-grade brain tumors tend to have lower serum GFAP levels [33]. 
This study has some limitations that must be addressed in further research. First, the sample size was relatively small; only 54 and 20 patients with low-grade and high-grade brain tumors, respectively, were enrolled. Accordingly, minor risk factors for poorer outcomes, such as low GFAP levels, as well as the lower survival rate in patients with higher serum lactate levels, may not have been detectable. Further investigation in a larger cohort is warranted. Second, only patients with supratentorial primary brain tumors were enrolled because this study was based on the design of an intraoperative fluid management study. Infratentorial brain tumors are typically more difficult to treat than supratentorial brain tumors; therefore, our results may not be completely applicable to patients with infratentorial tumors.

\section{MATERIALS AND METHODS}

\section{Patients}

A total of 74 cases of solitary supratentorial gliomas were retrieved from a patient cohort designed for intraoperative goal-directed fluid therapy at National Taiwan University Hospital (NTUH) during 2013-2015 (NCT02113358). This study was approved by the Ethics Review Committee of NTUH, with written informed consent obtained from all patients. Patients with a body mass index $>27$ or $<18.5$, congestive heart failure, renal dysfunction, or chronic obstructive pulmonary disease were excluded. In addition, patients with metastatic brain tumors or multiple brain tumors were excluded. Patients did not receive preoperative radiotherapy or chemotherapy.

\section{Demographic data, imaging, and pathology}

Data on patient demographics, comorbidities, tumor histology, and World Health Organization (WHO) tumor grading were analyzed. Tumors were classified as highgrade (WHO grade III, IV) or low-grade (WHO grade I, II). Tumor sizes were measured based on the longest tumor diameter in magnetic resonance imaging in a single axial section.

OS was calculated from the date of initial tumor resection to patient death. PFS was determined from the date of initial tumor resection to tumor recurrence or patient death.

\section{Serum biomarker assessment}

Levels of serum neuronal and nonneuronal biomarkers were assessed before tumor resection. Levels of the neuronal biomarkers, namely NSE (Alpha Diagnostic International, San Antonio, TX, USA), S100 $\beta$ (BioVendor LLC, Candler, NC, USA), and GFAP (BioVendor LLC, USA) were measured using enzyme- linked immunosorbent assay kits. Lactate levels were quantified using a blood gas analyzer (Stat Profile Critical Care Xpress, Nova Biomedical Cooperation, Waltham, MA, USA). LDH activity was assessed using an activity assay kit (Biovision, Milpitas, CA, USA).

\section{Statistical analysis}

The Student t test and Mann-Whitney U test were used for variables with a parametric distribution and a nonparametric distribution, respectively. The $\chi^{2}$ test or Fisher exact test was used for assessing the statistical significance of categorical variables. To identify factors associated with high-grade brain tumors, patient age, sex, body weight, comorbidities, and serum biomarkers (lactate, LDH, NGAL, GFAP, NSE, and S100 $\beta$ ) were included in the univariate and multivariate logistic regression analyses. Age, body weight, and serum biomarkers were used as continuous variables, and the remaining covariates were used as categorical variables.

A ROC curve was constructed to analyze independent predictors of tumor grading and to estimate the AUC, sensitivity, and specificity of the optimal cutoff value (calculated using Youden index).

OS and PFS were evaluated using the KaplanMeier method for univariate analysis, and differences were assessed using the log-rank test. Univariate and multivariate Cox proportional hazards regression models were used to investigate the effects of different variables on OS. Data were presented as the mean \pm standard deviation, and data were statistically analyzed using SPSS V20.0 software. Values of $p<0.05$ were considered statistically significant, and all $p$ values reported were twosided.

\section{CONCLUSION}

This study suggests that an elevated pretreatment serum lactate level is an independent predictor of poorer oncological outcomes, including shorter OS and PFS, and is associated with higher tumor grades in patients undergoing supratentorial primary brain tumor resection. By contrast, pretreatment levels of neuronal biomarkers, namely S100 $\beta$, NSE, and GFAP, and nonneuronal biomarkers, namely NGAL and LDH, were not associated with oncological outcomes.

\section{Abbreviations}

$\mathrm{HR}$, hazard ratio; CI, confidence interval; NSE, neuron-specific enolase; GFAP, glial fibrillary acidic protein; NGAL, neutrophil gelatinase-associated lipocalin; $\mathrm{OR}$, odds ratio; ROC, receiver operating characteristic; OS, overall survival; PFS, progression-free survival; LDH, lactate dehydrogenase; GBM, glioblastoma multiforme; 
WHO, World Health Organization; AUC, area under the curve

\section{Author contributions}

Conception of study design: Shih CC, Wu CY, and Cheng HL

Patient recruitment and data collection: Lee TS, Lin

PL, Wu CY, and Cheng HL

Data analysis: Shih CC, Tsuang FY, and Cheng YJ

Manuscript drafting: Shih $\mathrm{CC}$ and $\mathrm{Wu} \mathrm{CY}$

Critical revision for important intellectual content:

Lee TS, Tsuang FY, Wu CY, and Cheng HL

\section{ACKNOWLEDGMENTS}

We thank the staff of the Clinical Trial Center, $\mathrm{NTUH}$, for their assistance in statistical analysis.

\section{CONFLICTS OF INTEREST}

The authors declare no conflicts of interest.

\section{REFERENCES}

1. Yan T, Skaftnesmo KO, Leiss L, Sleire L, Wang J, Li X, Enger PO. Neuronal markers are expressed in human gliomas and NSE knockdown sensitizes glioblastoma cells to radiotherapy and temozolomide. BMC Cancer. 2011; 11: 524. https://doi.org/10.1186/1471-2407-11-524.

2. Vos MJ, Postma TJ, Martens F, Uitdehaag BM, Blankenstein MA, Vandertop WP, Slotman BJ, Heimans JJ. Serum levels of S-100B protein and neuron-specific enolase in glioma patients: a pilot study. Anticancer Res. 2004; 24: 2511-4.

3. Husain H, Savage W, Grossman SA, Ye X, Burger PC, Everett A, Bettegowda C, Diaz LA Jr, Blair C, Romans KE, Holdhoff M. Pre- and post-operative plasma glial fibrillary acidic protein levels in patients with newly diagnosed gliomas. J Neurooncol. 2012; 109: 123-7. https://doi. org/10.1007/s11060-012-0874-8.

4. Tichy J, Spechtmeyer S, Mittelbronn M, Hattingen E, Rieger J, Senft C, Foerch C. Prospective evaluation of serum glial fibrillary acidic protein (GFAP) as a diagnostic marker for glioblastoma. J Neurooncol. 2016; 126: 361-9. https://doi.org/10.1007/s11060-015-1978-8.

5. Smith ER, Zurakowski D, Saad A, Scott RM, Moses MA. Urinary biomarkers predict brain tumor presence and response to therapy. Clin Cancer Res. 2008; 14: 2378-86. https://doi.org/10.1158/1078-0432.CCR-07-1253.

6. Candido S, Maestro R, Polesel J, Catania A, Maira F, Signorelli SS, McCubrey JA, Libra M. Roles of neutrophil gelatinase-associated lipocalin (NGAL) in human cancer. Oncotarget. 2014; 5: 1576-94. https://doi.org/10.18632/ oncotarget. 1738 .
7. Romero-Garcia S, Moreno-Altamirano MM, Prado-Garcia H, Sanchez-Garcia FJ. Lactate contribution to the tumor microenvironment: mechanisms, effects on immune cells and therapeutic relevance. Front Immunol. 2016; 7: 52. https://doi.org/10.3389/fimmu.2016.00052.

8. Mariappan R, Venkatraghavan L, Vertanian A, Agnihotri S, Cynthia S, Reyhani S, Tung T, Khan OH, Zadeh G. Serum lactate as a potential biomarker of malignancy in primary adult brain tumours. J Clin Neurosci. 2015; 22: 144-8. https://doi.org/10.1016/j.jocn.2014.06.005.

9. Zhang J, Yao YH, Li BG, Yang Q, Zhang PY, Wang HT. Prognostic value of pretreatment serum lactate dehydrogenase level in patients with solid tumors: a systematic review and meta-analysis. Sci Rep. 2015; 5: 9800. https://doi.org/10.1038/srep09800.

10. Lu J, Tan M, Cai Q. The Warburg effect in tumor progression: mitochondrial oxidative metabolism as an anti-metastasis mechanism. Cancer Lett. 2015; 356: 15664. https://doi.org/10.1016/j.canlet.2014.04.001.

11. Choi SY, Collins CC, Gout PW, Wang Y. Cancer-generated lactic acid: a regulatory, immunosuppressive metabolite? J Pathol. 2013; 230: 350-5. https://doi.org/10.1002/path.4218.

12. Liberti MV, Locasale JW. The Warburg effect: how does it benefit cancer cells? Trends Biochem Sci. 2016; 41: 211-8. https://doi.org/10.1016/j.tibs.2015.12.001.

13. Tennant DA, Duran RV, Boulahbel H, Gottlieb E. Metabolic transformation in cancer. Carcinogenesis. 2009; 30: 126980. https://doi.org/10.1093/carcin/bgp070.

14. Walenta S, Mueller-Klieser WF. Lactate: mirror and motor of tumor malignancy. Semin Radiat Oncol. 2004; 14: $267-$ 74. https://doi.org/10.1016/j.semradonc.2004.04.004.

15. Li Y, Lupo JM, Parvataneni R, Lamborn KR, Cha S, Chang SM, Nelson SJ. Survival analysis in patients with newly diagnosed glioblastoma using pre- and postradiotherapy MR spectroscopic imaging. Neuro Oncol. 2013; 15: 60717. https://doi.org/10.1093/neuonc/nos334.

16. Saraswathy S, Crawford FW, Lamborn KR, Pirzkall A, Chang S, Cha S, Nelson SJ. Evaluation of MR markers that predict survival in patients with newly diagnosed GBM prior to adjuvant therapy. J Neurooncol. 2009; 91: 69-81. https://doi.org/10.1007/s11060-008-9685-3.

17. Yamasaki F, Kurisu K, Kajiwara Y, Watanabe Y, Takayasu T, Akiyama Y, Saito T, Hanaya R, Sugiyama K. Magnetic resonance spectroscopic detection of lactate is predictive of a poor prognosis in patients with diffuse intrinsic pontine glioma. Neuro Oncol. 2011; 13: 791-801. https://doi. org/10.1093/neuonc/nor038.

18. Walenta S, Salameh A, Lyng H, Evensen JF, Mitze M, Rofstad EK, Mueller-Klieser W. Correlation of high lactate levels in head and neck tumors with incidence of metastasis. Am J Pathol. 1997; 150: 409-15.

19. Brizel DM, Schroeder T, Scher RL, Walenta S, Clough RW, Dewhirst MW, Mueller-Klieser W. Elevated tumor lactate concentrations predict for an increased risk of metastases in 
head-and-neck cancer. Int J Radiat Oncol Biol Phys. 2001; 51: 349-53. https://doi.org/10.1016/s0360-3016(01)01630-3.

20. Walenta S, Wetterling M, Lehrke M, Schwickert G, Sundfor K, Rofstad EK, Mueller-Klieser W. High lactate levels predict likelihood of metastases, tumor recurrence, and restricted patient survival in human cervical cancers. Cancer Res. 2000; 60: 916-21.

21. Boumezbeur F, Petersen KF, Cline GW, Mason GF, Behar KL, Shulman GI, Rothman DL. The contribution of blood lactate to brain energy metabolism in humans measured by dynamic $13 \mathrm{C}$ nuclear magnetic resonance spectroscopy. J Neurosci. 2010; 30: 13983-91. https://doi.org/10.1523/ JNEUROSCI.2040-10.2010.

22. Dienel GA. Brain lactate metabolism: the discoveries and the controversies. J Cereb Blood Flow Metab. 2012; 32: 1107-38. https://doi.org/10.1038/jcbfm.2011.175.

23. Verma A, Kumar I, Verma N, Aggarwal P, Ojha R. Magnetic resonance spectroscopy - revisiting the biochemical and molecular milieu of brain tumors. BBA Clin. 2016; 5: 1708. https://doi.org/10.1016/j.bbacli.2016.04.002.

24. McCrea HJ, Bander ED, Venn RA, Reiner AS, Iorgulescu JB, Puchi LA, Schaefer PM, Cederquist G, Greenfield JP. Sex, age, anatomic location, and extent of resection influence outcomes in children with high-grade glioma. Neurosurgery. 2015; 77: 443-52; discussion 52-3. https:// doi.org/10.1227/NEU.0000000000000845.

25. Sun T, Plutynski A, Ward S, Rubin JB. An integrative view on sex differences in brain tumors. Cell Mol Life Sci. 2015; 72: 3323-42. https://doi.org/10.1007/s00018-015-1930-2.

26. Chakraborty S, Kaur S, Guha S, Batra SK. The multifaceted roles of neutrophil gelatinase associated lipocalin (NGAL) in inflammation and cancer. Biochim Biophys Acta. 2012; 1826: 129-69. https://doi.org/10.1016/j.bbcan.2012.03.008.
27. Isgro MA, Bottoni P, Scatena R. Neuron-specific enolase as a biomarker: biochemical and clinical aspects. Adv Exp Med Biol. 2015; 867: 125-43. https://doi. org/10.1007/978-94-017-7215-0_9.

28. Vogelbaum MA, Masaryk T, Mazzone P, Mekhail T, Fazio V, McCartney S, Marchi N, Kanner A, Janigro D. S100beta as a predictor of brain metastases: brain versus cerebrovascular damage. Cancer. 2005; 104: 817-24. https:// doi.org/10.1002/cncr.21220.

29. Weide B, Richter S, Buttner P, Leiter U, Forschner A, Bauer J, Held L, Eigentler TK, Meier F, Garbe C. Serum S100B, lactate dehydrogenase and brain metastasis are prognostic factors in patients with distant melanoma metastasis and systemic therapy. PLoS One. 2013; 8: e81624. https://doi. org/10.1371/journal.pone.0081624.

30. Kahn HJ, Baumal R, Van Eldik LJ, Dunn RJ, Marks A. Immunoreactivity of S100 beta in heart, skeletal muscle, and kidney in chronic lung disease: possible induction by cAMP. Mod Pathol. 1991; 4: 698-701.

31. Jung CS, Foerch C, Schanzer A, Heck A, Plate KH, Seifert V, Steinmetz H, Raabe A, Sitzer M. Serum GFAP is a diagnostic marker for glioblastoma multiforme. Brain. 2007; 130: 3336-41. https://doi.org/10.1093/brain/awm263.

32. Wilhelmsson U, Eliasson C, Bjerkvig R, Pekny M. Loss of GFAP expression in high-grade astrocytomas does not contribute to tumor development or progression. Oncogene. 2003; 22: 3407-11. https://doi.org/10.1038/sj.onc.1206372.

33. Chumbalkar VC, Subhashini C, Dhople VM, Sundaram CS, Jagannadham MV, Kumar KN, Srinivas PN, Mythili R, Rao MK, Kulkarni MJ, Hegde S, Hegde AS, Samual C, et al. Differential protein expression in human gliomas and molecular insights. Proteomics. 2005; 5: 1167-77. https:// doi.org/10.1002/pmic.200401202. 